EESTI NŚV TEADUSTE AKADEEMIA TOIMETISED. VI KOIDE BIOLOOGILINE SEERIA. 1957. NR. 2

ИЗВЕСТИЯ АКАДЕМИИ НАУК ЭСТОНСКОЙ ССР. ТОМ VI СЕРИЯ БИОЛОГИЧЕСКАЯ. 1957, № 2

\title{
ОСАДКА ТОРФА ПРИ ОСУШЕНИИ БОЛОТ
}

\section{У. Х. ТОМБЕРГ}

При понижении уровня грунтовых вод в результате осушения болот верхний, осушенный слой торфяника оказывает дополнительное давление, равное его весу, на нижележащие слои. Вследствие этого происходит сжатие нижележащих слоев торфяной залежи. Увеличение давления является причиной уплотнения нижних слоев торфяника. Верхние, осушенные слои уплотняются под влиянием собственного веса, усыхания, капиллярных сил и механического уплотнения при проведении сельскохозяйственных работ. Уплотнение торфяной залежи или осадка торфа охватывает, таким образом, все слои залежи торфяника от минерального дна до поверхности болота. Вследствие осадки торфа после осушения болота уменьшается мощность торфяной залежи и глубина закладки осушительной сети, происходит осадка дна канав и дрен. Все это ухудшает работу осушительной сети, а иногда может быть и причиной полного прекращения действия осушительных систем. Поэтому необходимо правильно учитывать величину осадки торфа.

Для определения величин осадки предложено много способов, которые, к сожалению, имеют ряд недостатков. Так, например, в таблицах Гергардта [ $\left.{ }^{6}\right]$, ВНИИГиМ [ $\left.{ }^{1}\right]$ и в формулах Д. А. Панадиади $\left.{ }^{2}\right]$ используются факторы, оценка которых производится на субъективной основе (плотность торфа), а формулы А. Ф. Печкурова [ $\left.{ }^{4}\right]$ требуют предварительной оценки изменения объемного веса и зольности торфа после его осушения. Формулы Халлакорпи же [5] не учитывают физические свойства торфа. Определенне осадки по компрессионным свойствам торфа практически не применяется, что вызвано трудоемкостью определения компрессионной кривой торфяной залежи. Кроме того, все формулы для определения осадки торфа являются региональными, так как свойства торфов зависят от местных условий и не могут быть механически использованы в других климатических условиях.

Для условий Әстонской ССР вопросы осадки торфа разработаны еще недостаточно.

\section{Факторы осадки торфа}

Осадка торфа вблизи осушителей зависит главным образом от глубины понижения грунтовых вод, т. е. от глубины осушителей, поскольку размер понижения грунтовых вод является функцией глубины осушителей. Осадка торфа увеличивается с увеличением глубины заложения осушителей (табл. 1 и 6).

Таблица 1

Осадка поверхности болота в зависимости от интенсивности осушения

\begin{tabular}{|c|c|c|c|c|c|}
\hline Глубина заложения дрен, м & 1,05 & 1,15 & 1,25 & 1,35 & 1,45 \\
\hline Осадка поверхности, м & 0,32 & 0,36 & 0,38 & 0,40 & 0,44 \\
\hline $\begin{array}{l}\text { Осадка поверхности в \% от мощно- } \\
\text { сти залежи }\end{array}$ & 10,3 & 12,0 & 12,7 & 13,4 & 14,7 \\
\hline
\end{tabular}


В табл. 1 приведены данные об осадке торфа вблизи дрен за первый год после осушения тростниково-осокового болота со степенью разложения $25 \%$ и мощностью залежи в среднем 3,0 м (в совхозе Ойдремаа).

Как указывалось выше, осадка торфа зависит от мощности залежи при одной и той же интенсивности осушения осадка тем больше, чем больше мощность залежи.

В табл. 2 приведена величина осадки торфа за первый год после осушения тростниково-осокового болота на полях Тоомаской опытной базы Эстонского научно-исследовательского института земледелия и мелиорации (ЭНИИЗМ). Болото было осушено в 1935 г. дренажем глубиной 0,90 м.

Таблица 2

Осадка поверхности болота в зависимости от мощности залежи

\begin{tabular}{l|c|c|c|c}
\hline Мощность залежи, м & 1,7 & 3,5 & 4,5 & 5,5 \\
\hline Осадка поверхности, м & 0,29 & 0,39 & 0,45 & 0,49 \\
\hline $\begin{array}{c}\text { Осадка поверхности в \% от } \\
\text { мощности залежи }\end{array}$ & 17,1 & 11,2 & 10,0 & 8,9
\end{tabular}

Данные табл. 2 показывают, что при одной и той же степени осушения осадка менее мощных залежей относительно больше осадки более глубоких залежей.

Осадка торфа зависит от степени его разложения. С увеличением 'степени разложения (при прочих равных условиях) осадка уменьшается, так как в процессе разложения торфа увеличиваются его плотность и объемный вес. В табл. 3 приведены данные об осадке торфа на по́лях Тоомаской базы ӘНИИзМ и в совхозе Ойдремаа за первый год после осушения. Торф этих болот тростниково-осоковый и мощность залежи составляет в среднем 3,0 м.

Таблица 3

Осадка торфа (в м) в зависимости от степени разложения

\begin{tabular}{l|c|c|c|c}
\hline Глубина дрен, м & \multicolumn{2}{|c|}{1,05} & \multicolumn{2}{|c}{1,35} \\
\cline { 1 - 4 } Осадка & $\begin{array}{c}\text { поверх- } \\
\text { ности }\end{array}$ & дрен & $\begin{array}{c}\text { поверх- } \\
\text { ности }\end{array}$ & дрен \\
\hline $\begin{array}{l}\text { Tоома (степень разложения } \\
40 \% \text { ) }\end{array}$ & 0,223 & 0,045 & 0,297 & 0,04 \\
\hline $\begin{array}{l}\text { Оh̆дремаa (степень разложения } \\
25 \% \text { ) }\end{array}$ & 0,32 & 0,13 & 0,40 & 0,086
\end{tabular}

Кроме ботанического состава, осадка торфа зависит также от типа болота. Осадка верховых болот больше осадки низинных. Кроме того, осадка является функцией ряда других факторов, как плотность, зольность, объемный вес и т. д. Ввиду сложности явления, осадка торфа не может быть полностью охарактеризована простейшими формулами. 


\section{Изменение размеров осадки торфа в зависимости от времени}

Наблюдениями установлено, что осадка торфа продолжается и после проведения осушительных работ в течение очень длительного периода. Наибольшая интенсивность осадки наблюдается в первое время после осушения. Со временем интенсивность осадки уменьшается. Примерно после 2-5 лет осушения, в зависимости от интенсивности осушения и климатических условий, она становится сравнительно равномерной (рис. 1 и табл. 4 ).

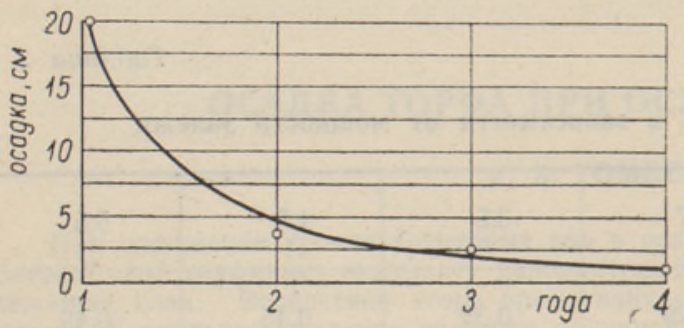

Рис. 1. Ежегодная осадка болота в Тоома.

Причиной осадки до момента стабилизации ее $(2-5$ лет $)$ является понижение уровня грунтовых вод, т. е. осушение болот. Дальнейшая осадка обусловливается минерализацией торфа, которая піроисходит под влиянием сельскохозяйственного использования осушенных торфяников и называется В. Н. Грамматиным $\left[^{3}\right]$ «сработкой» торфа.

Таблица 4

Ежегодная осадка торфа в Тоома

\begin{tabular}{l|c|c|c|c|c|c|c|c|c}
\hline $\begin{array}{c}\text { Время, прошедшее } \\
\text { после осушения } \\
\text { (в годах) }\end{array}$ & 1 & 2 & 3 & 4 & 5 & 6 & 7 & 8 & 9 \\
\hline Осадка, см & 44 & $?$ & $?$ & 5 & 6 & 2 & 1 & 2 & 2 \\
\hline
\end{tabular}

Табл. 4 составлена по данным осушения болота в Тоома, осуществленного дренажем глубиной 0,90 м (мощность залежи составляла здесь в среднем 4,5 м), а рис. 1 - по данным участка в Тоома, где средняя глубина дрен равнялась 0,85 м и мощность залежи - 3,9 м.*

Судя по имеющимся для осушенных болот ӘССР данным (рис. 1 и табл. 4), ежегодная сработка болот республики составляет $1-2$ см.

Дальнейшее рассмотрение проблемы ограничивается изучением вопроса об осадке торфа в зависимости от понижения грунтовых вод.

\section{Распределение осадки по глубине торфяной залежи}

На рис. 2 приведены эпюры распределения осадки по глубине залежи для некоторых болот ӘССР. Эпюры относительной осадки получены из эпюр абсолютной осадки. Зону осадки можно разделить на две части: зону, расположенную выше заложения осушителей, и зону, расположенную ниже их заложения. Осадка верхней зоны обычно превышает размеры осадки нижней зоны. Однако встречаются болота, в которых относительные осадки этих зон равны, а в некоторых случаях осадка нижней зоны больше, чем верхней.

* Данные за 2 и 3 годы в табл. 4 отсутствуют, так как нивелировка во 2 году не производилась. 

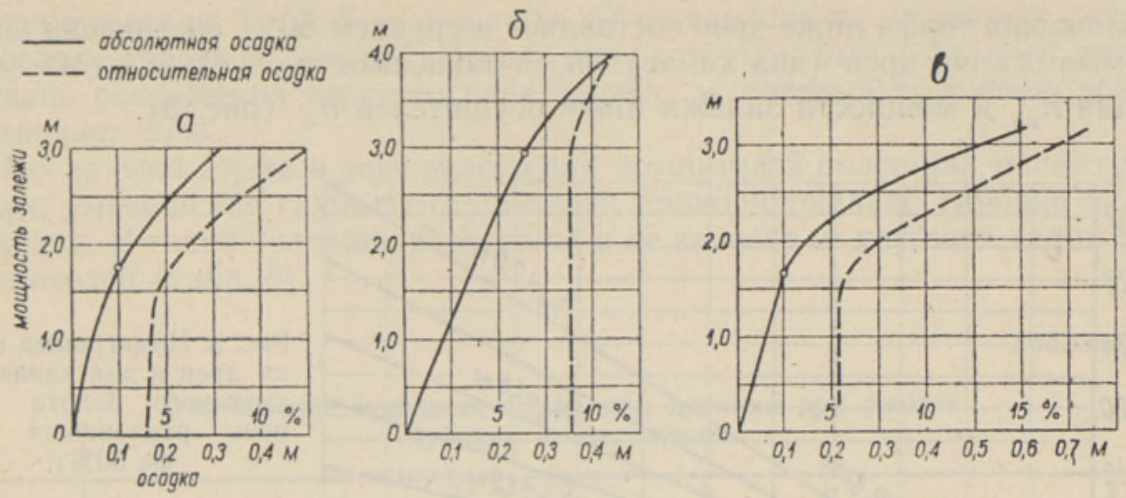

Рис. 2. Эпюры распределения осадки по глубине залежи: $a-$ болота совхоза Ойдремаа; 6 - болота совхоза Камбья; $в$ - по данным Э. Тоомингаса [?].

В зоне, расположенной ниже осушителей, эпюра относительной осадки имеет форму прямоугольника. Это значит, что в нижней зоне относительная осадка является постоянной, или

$$
\frac{\Delta h_{\mathrm{H}}}{h_{\mathrm{H}}}=A \text {, }
$$

где $\Delta h_{\text {н }}$ - осадка торфа ниже глубины заложения осушителей;

$h_{\text {н }}$ - мощность залежи ниже глубины заложения осушителей до осадки торфа;

$A$ - коэффициент осадки слоя торфа ниже осушителей.

Эпюру абсолютной осадки верхней зоны можно рассматривать как эпюру треугольной формы, так как кривизна ее незначительна. Это значит, что и в этой зоне относительная осадка (уменьшение слоя над дреной) является примерно постоянной, или

$$
\frac{\Delta h_{\mathrm{o}}}{h_{\mathrm{o}}}=B,
$$

где $\Delta h_{\text {o }}$ - уменьшение глубины осушителя;

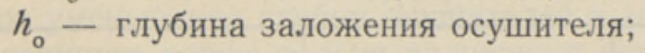

$B$ - коэффициент уменьшения глубины заложения осушителя.

Осадка поверхности болота является суммой осадки в этих двух зонах.

Осадка слоя торфа ниже глубины заложения осушителей зависит от глубины заложения осушителя, от мощности залежи ниже осушителей и от степени разложения торфа, от которой, в свою очередь, зависит и плотность торфа.

При однородном строении, одинаковых физических свойствах всех слоев торфяной залежи ниже заложения осушителей и при определенном давлении величина $A$ является постоянной.

В природе, однако, редко встречаются однородные торфяные залежи. Обычно нижние слои, как более старые, являются и более уплотненными. В таких условиях точная характеристика коэффициента осадки нижнего слоя $A$ является крайне затруднительной. В данном случае возможно лишь приближенное решение вопросов осадки. На основе обработки данных 4-летних наблюдений об осадке дрен, заложенных на глубину от 0,4 до 1,3 м на полях Тоомаской опытной базы ӘНИИЗМ в 1948 году, где мощность залежи низинного болота изменяется от 1,6 до 6,7 м, а степень 
разложения торфа ниже дрен составляет в среднем $50 \%$, составлена номограмма осадки дрен (дна канав) $\Delta h_{\text {н }}$ в зависимости от глубины их заложения $h_{\text {пр }}$ и мощности залежи ниже осушителей $h_{\text {н }}$ (рис. 3 ).

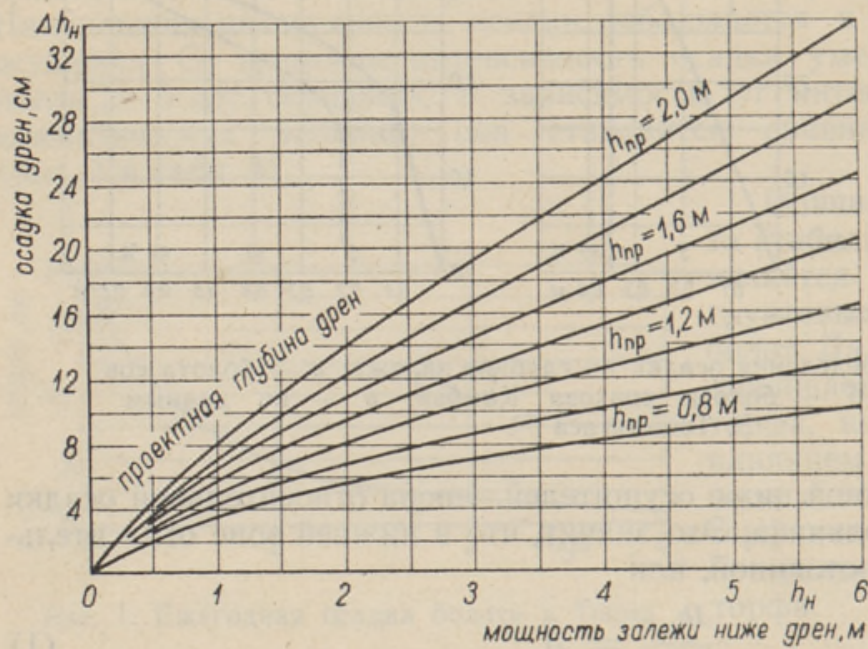

Рис. 3. Номограмма осадки дрен и дна канав для низинного болота (степень разложения торфа $50 \%)$.

На низинном болоте Ойдремаа, где степень разложения торфа ниже осушителей составляет $30 \%$, дрены и дно канав осели в 1,8 раза больше, чем в Тоома. Ввиду этого для низинных торфяников со степенью разложения торфа ниже осушителей в $40 \%$ и $30 \%$, приведенные в номограмме (рйс. 3) величины осадки следует умножить соответственно на 1,4 и 1,8.

Уменьшение глубины осушителей зависит только от глубины их заложения и от физических свойств торфа. Коэффициент уменьшения глубины осушителя $B$, как это видно из табл. 5 , не зависит от мощности залежи

Таблица 5

Коэффициент уменьшения глубины осушителей $B$ при разных мощностях залежи торфа ниже дрен

\begin{tabular}{c|c|c|c}
\hline Число точек & $\begin{array}{c}\text { Средняя глубина } \\
\text { заложения дрен, } \\
\text { м }\end{array}$ & $\begin{array}{c}\text { Мощность залежи } \\
\text { ниже дрен, } \\
\text { м }\end{array}$ & $\begin{array}{c}\text { Коэффициент умень- } \\
\text { шения глубины } \\
\text { осушителей }\end{array}$ \\
\hline \hline 19 & 1,10 & 1,11 & 0,242 \\
\hline 168 & 0,87 & 2,21 & 0,237 \\
\hline 86 & 0,83 & 3,14 & 0,224 \\
\hline 36 & 0,83 & 4,13 & 0,259 \\
\hline 61 & 0,74 & 5,40 & 0,224 \\
\hline 370 & \multicolumn{2}{c}{ Средневзвешенный } & 0,234 \\
\hline
\end{tabular}


ниже осушителя. Табл. 5 (как и табл. 6) составлена на основании данных об осадке участков болота в Тоома, по которым был составлен рис. 3 . Степень разложения верхнего слоя торфа, в который заложены дрены, составляет $30 \%$.

Когда слой торфа в зоне заложения осушителей более или менее однороден, уменьшение глубины осушителей пропорционально глубине их заложения. В таких условиях $B=$ const и не зависит от глубины заложения осушителей (табл. 6).

Таблица 6

\section{Уменьшение мощности торфа над дренами при разных глубинах их заложения}

\begin{tabular}{|c|c|c|c|c|c|c|}
\hline \multirow{2}{*}{$\begin{array}{l}\text { Число } \\
\text { точек }\end{array}$} & \multicolumn{2}{|c|}{ Глубина } & \multicolumn{2}{|c|}{ Осадка } & \multicolumn{2}{|c|}{$\begin{array}{c}\text { Уменьшение глубины } \\
\text { заложения дрен }\end{array}$} \\
\hline & $\begin{array}{c}\text { залежи } \\
\text { торфа, } \\
\text { м }\end{array}$ & $\begin{array}{c}\text { заложения } \\
\text { дрен, } \\
\text { м }\end{array}$ & $\begin{array}{c}\text { поверхности, } \\
\text { м }\end{array}$ & $\begin{array}{l}\text { дрен, } \\
\text { м }\end{array}$ & M & B \\
\hline $\begin{array}{r}6 \\
19 \\
22 \\
25 \\
19 \\
20 \\
20 \\
20 \\
11 \\
6\end{array}$ & $\begin{array}{r}2,73 \\
2,95 \\
2,97 \\
3,03 \\
3,20 \\
3,18 \\
3,11 \\
3,13 \\
3,11 \\
3,23\end{array}$ & $\begin{array}{l}1,32 \\
1,19 \\
1,10 \\
1,01 \\
0,89 \\
0,79 \\
0,69 \\
0,59 \\
0,48 \\
0,40\end{array}$ & $\begin{array}{l}0,380 \\
0,339 \\
0,309 \\
0,302 \\
0,304 \\
0,275 \\
0,256 \\
0,221 \\
0,154 \\
0,162\end{array}$ & $\begin{array}{l}0,070 \\
0,074 \\
0,070 \\
0,077 \\
0,074 \\
0,085 \\
0,083 \\
0,071 \\
0,057 \\
0,048\end{array}$ & $\begin{array}{l}0,310 \\
0,265 \\
0,239 \\
0,225 \\
0,230 \\
0,190 \\
0,173 \\
0,150 \\
0,097 \\
0,114 \\
\end{array}$ & $\begin{array}{l}0,235 \\
0,223 \\
0,217 \\
0,223 \\
0,258 \\
0,240 \\
0,250 \\
0,254 \\
0,203 \\
0,285\end{array}$ \\
\hline 168 & \multicolumn{5}{|c|}{ Средневзвешенный* } & 0,237 \\
\hline
\end{tabular}

* Средняя квадратичная ошибка среднего взвешенного $\sigma= \pm 0,020$.

Из приведенных данных вытекает, что уменьшение глубины заложения осушителей можно охарактеризовать коэффициентом $B$, причем величина его зависит только от физических свойств торфа.

Средние размеры определенных в разных районах ӘССР коэффициентов уменьшения глубин осушителей в зависимости от степени разложения низинного торфа в зоне заложения осушителей приводятся в табл. 7 .

\section{Проектная глубина осушителей}

Коэффициенты уменьшения глубин заложения осушителей характеризуют ту осадку, которая происходит в течение первых 2-4 лет после осушения торфяника. Выше было показано, что после основной осадки торфа происходит еще процесс оработки торфяника, ежегодная величина которой составляет $1-2$ см. При расчете проектной глубины дрен следует учитывать и эту величину.

Полагая, что средний срок службы дрен при осушении болот наиболее распространенного в практике деревянного дренажа составляет 20 лет, и допуская, что средняя глубина грунтовых вод в первой половине эксплуатационного периода немного больше, а во второй половине немного меньше оптимальной глубины, расчетная величина сработки при средней величине ежегодной сработки в 1,5 см (в течение первой половины эксплуатационного периода) составляет в среднем $D=10 \times 1,5=15$ см. 
Для гончарного дренажа (срок службы 30-40 лет) расчетная величина сработки составляет соответственно 25 см. Таким образом, глубина осушителей в половине срока их службы будет следующей:

$$
\begin{gathered}
h=h_{\text {пр }}-B h_{\text {пр }}-D, \\
\text { или } \\
h_{\text {пр }}=\frac{h+D}{1-B},
\end{gathered}
$$

так как по (2) $\Delta h_{\text {пр }}=B h_{\text {nр }}$.

$$
\begin{gathered}
\text { Обозначая } \frac{1}{1-B}=C, \quad \text { формула (3) получит вид } \\
h_{\text {пр }}=C(h+D),
\end{gathered}
$$

где $h_{\text {nр }}$ - проектная глубина осушителей в метрах;

\section{таблица 7}

Расчетные величины коэффициентов $B$ и $C$

\begin{tabular}{c|c|c}
\hline $\begin{array}{c}\text { Cтепень разложения } \\
\text { низинного торфа, \% }\end{array}$ & B & C \\
\hline & & \\
50 & 0,17 & 1,20 \\
40 & 0,20 & 1,25 \\
30 & 0,23 & 1,30 \\
20 & 0,26 & 1.35
\end{tabular}

C - коэффициент, определяется из табл. 7 по степени разложения торфа; *

$h$ - требуемая глубина осушителей после осадки торфа в м;

$D$ - сработка залежи в м (для гончарного дренажа $D=0,25 \mathrm{м}$, для деревянного дренажа $-0,15 \mathrm{~m})$.

* В табл. 7 представлены первоначальные данные исследований.

\section{Уменьшение уклона приустьевой части дрен в период производства строительных работ}

При осушении торфяных почв дрены обычно проектируются и закладываются с одинаковым уклоном по всей их длине. Дренажным работам всегда предшествует рытье открытых собирательных канав. Укладка же дрен производится спустя несколько месяцев, а иногда и через год или два после отрывки собирательных канав. За это время торф в приканавных зонах оседает, причем наибольшая осадка происходит непосредственно у канавы. После проведения дренажных работ оседание происходит по всей длине дрен. Но так как осадка в приканавной зоне к моменту отрывки дренажных канав уже почти закончена, дрены в этой зоне в дальнейшем оседают сравнительно мало. После осадки дрен их уклон в при-

\begin{tabular}{|c|c|c|c|c|}
\hline \multirow{2}{*}{$\begin{array}{c}\text { Место } \\
\text { заложения дрен }\end{array}$} & \multirow{2}{*}{$\begin{array}{l}\text { Длина при- } \\
\text { канавного } \\
\text { участка, м }\end{array}$} & \multicolumn{2}{|c|}{ Уклон дрен } & \multirow{2}{*}{$\begin{array}{c}\text { Среднее } \\
\text { из }\end{array}$} \\
\hline & & $\begin{array}{c}\text { в приканав- } \\
\text { ной части }\end{array}$ & $\begin{array}{l}\text { в остальной } \\
\text { части }\end{array}$ & \\
\hline $\begin{array}{l}\text { ЭНИизМ - Тоома } \\
\text { ЭНИИЗМ - Тоома } \\
\text { Совхоз Ойдремаа } \\
\text { Совхоз Ойдремаа }\end{array}$ & $\begin{array}{l}10 \\
20 \\
85 \\
85\end{array}$ & $\begin{array}{c}-0,002 \\
0,002 \\
0,0029 \\
0,0009\end{array}$ & $\begin{array}{l}0,0026 \\
0,0046 \\
0,003 \\
0,0025\end{array}$ & $\begin{array}{r}36 \text { дрен } \\
22 \text { дрен } \\
7 \text { дрен } \\
13 \text { дрен }\end{array}$ \\
\hline
\end{tabular}
канавной зоне оказывается меньше, чем в зонах, расположенных в большем отдалении от канавы (табл. 8).

Уменьшение уклона дрен в приканавной зоне

Таблица 8 
Такое уменьшение уклона дрены, особенно в устьевой части ее, является причиной уменьшения пропускной способности дрен и может послужить причиной заиления последних. Для предотвращения уменьшения уклона дрен в приустьевой части выполнение дренажных работ следует организовать одновременно с прокопкой собирателей либо - если время рытья траншей для дрен запаздывает по отношению к срокам отрывки открытых собирателей - увеличивать глубину закладки дрен в приканавной зоне.

\section{ЛИТЕРАТУРА}

1. Справочник по мелиорации и сельскохозяйственному использованию болот. Изд. Академии наук БССР, Минск, 1954.

2. Ге йтм ан Б. Г. и Пи с а рьков Х. А., Осушение сельскохозяйственных земель. М.-Л., 1955.

3. Г рам м ати н В. Н., Осадка болот при осушенни для сельскохозяйственных целей. Материалы по поднятию производительности с.-х. земель посредством мелиорации. Выпуск IX. Гидротехнический сборник. СНИИГиМ. Ленинград, 1939.

4. Пе ч куров А. Ф., Устойчивость русла регулированных рек. Минск, 1950.

5. K a iter a, P. Om uppskattning av markytans sättning vid torrläggningsarbetena, Nordisk Jordbrugsforskning, Häfte 1-4. Årgång 36. Stockholm, 1954.

6. K n a u e r, H. Meliorationen. Strelitz in Mecklenburg.

7. To o ming a s, E. Maaparanduse ōpik. Tallinn, 1949.

\section{Эстонский научно-исследовательский институт Поступила в редакцию 'емледелия и мелиорации \\ 22 XII 1956}

\section{TURBA VAJUMINE SOODE KUIVENDAMISEL}

\section{U. Tomberg}

\section{Resümee}

Soode kuivendamisel kaotab turbalasundi ülemine kiht ujuvuse ja surub oma raskusega allpoolasuvatele turbakihtidele, põhjustades nende vajumise. Kuivendatav turbakiht ise aga vajub omaenda raskuse, kokkutõmbumise, kapillaarjõudude ja pōllutöömasinate surve mõjul. Seega vajuvad kõik turbakihid, soo mineraalsest aluspổhjast kuni pinnani.

Turba vajumine on vördeline lasundi tüseduse ja kuivendajate sügavusega ning pöördvõrdeline lagunemisastmega. Kuid vajumise suurus oleneb veel turba tihedusest, tema mahukaalust, tuhasusest, botaanilisest koostisest jne. Kogu selle nähtuse keerulisuse tõttu osutub turba võimaliku vajumise täpne väljaarvutamine praktiliselt väga raskeks.

Ka on turba vajumise määramiseks kasutatavatel meetoditel rida puudusi. Nii antakse vajumine Gerhardt'i tabelites ja $\mathrm{P}$ a nadia di valemites, lähtudes turba tihedusest, mis on defineeritud aga subjektiivselt. P e ť̌k urovi valemite kasutamine eeldab vajumise käigus toimuvate turba tuhasuse ja mahukaalu mutumiste esialgset hinnangut jne. Kuna turba vajumine oleneb ka klimaatilistest tingimustest, siis on kōik need meetodid pealegi regionaalse iseloomuga ning nad pole teistesse tingimustesse mehaaniliselt ülekantavad.

Turba vajumise intensiivsus on kõige suurem vahetult pärast kuivendustöid ja väheneb seejärel pidevalt, stabiliseerudes $2 .-5$. aastal pärast soo kuivendamist.

Turba esialgse vajumise (kuni stabiliseerumiseni) põhjuseks on pōhjaveetaseme alandamine. Edasist vajumist põhjustab turba lagunemine ja selle suurus on keskmiselt $1-2 \mathrm{~cm}$ aastas.

Kuivendamisest pōhjustatud turba vajumist võib vaadelda kahes osas: 1) kuivendajatest sügavamal asetseva turbakihi vajumine ja 2) kuivendajate sügavuse vähenemine. Nende summa annab soopinna vajumise. Kuivendajate alla jäăva turbakihi vajumine oleneb selle kihi tüsedusest, kuivendajate sügavusest ja turba lagunemisastmest. Dreenide ja kraavipōhjade vajumise määramiseks $50 \%$-lise lagunemisastmega madalsooturbas vōib kasutada vastavat nomogrammi (joon. 3). Kui turba lagunemisaste on 40 vooi $30 \%$, tuleb joonisel toodud vajumissuurusi suurendada vastavalt 1,4 vōi 1,8 korda. Nagu näitavad vaatluste andmed, oleneb kuivendajate sügavuse suhteline vähenemine ainult turba füüsikalistest omadustest, seega ka lagunemisastmest, ega olene kuivendajate alla jääva turbakihi tüsedusest ega kuivendajate sügavusest. Olaltoodust lähtudes on tuletatud valem kuivendajate projekteeritavate sügavuste arvutamiseks:

$$
h_{\mathrm{np}}=C(h+D) \text {, }
$$

kus $h_{\text {пр }}-$ kuivendajate sügavus meetrites; 
$C$ - koefitsient, määratakse vastavalt turba lagunemisastmele tabel 7 pōhjal;

$h$ - kuivendajate soovitav sügavus pärast turba vajumist meetrites;

$D$ - kuivendajate sügavuse vähenemine, olenevalt turba lagunemisest - puitmaterjalidest dreenide puhul $D=0,15 \mathrm{~m}$, savitorudrenaaži puhul $D=0,25 \mathrm{~m}$.

Soode kuivendamisel kaevatakse dreenikaevikud tavaliselt mōni aeg pärast lahtiste kogujakraavide kaevamist. Sellel ajavahemikul toimub aga turba vajumine kogujakraavi mơjupiirkonnas. Pärast dreenikaevikute kaevamist vajuvad ka nende pōhjad. Kuna turba vajumine kogujakraavi tsoonis on juba toimunud, siis vajuvad dreenid siin tunduvalt vähem kui văljaspool kraavi mōjupiirkonda. Selle tagajärjel väheneb dreeni lang kogujakraavipoolses osas ja vastavalt väheneb ka dreeni kuivendusvõime. Et vältida dreeni suudmeosas tema langu vähenemist, tuleb drenaažitööd teostada samaaegselt kogujakraavide kaevamisega vôi siis suurendada dreenide sügavust suudmeosas temale seal suurema langu andmiseks.

Eesti Maaviljeluse ja Maaparanduse

Teadusliku Uurimise Instituut

Saabus toimetusse

22. XII 1956

\section{SACKUNG DER MOORE INFOLGE DER ENTWÄSSERUNG}

\section{U. Tomberg}

\section{Zusammenfassung}

Nach der Entwässerung wird der schwimmende Gleichgewichtszustand des Moores gestört und die entwässerte Moorschicht wirkt als Auflast auf die darunter liegenden Moorschichten. Die Sackung der entwässerten Moorschichten wird von dem Eigengewicht, dem Schrumpfen, den Kapillaritätskräften und der Bearbeitung bewirkt. An den Sackungen sind alle Moorschichten, herab bis auf den mineralischen Untergrund, beteiligt.

Die Sackung steht in direktem Verhältnis zur Tiefe der Entwässerung und zur Mächtigkeit des Moores, sowie in umgekehrtem Verhältnis zur Dichtigkeit und dem Zersetzungsgrade des Torfes. Das Mass des Setzens hängt noch von der botanischen Zusammensetzung, dem Volumgewicht und anderen Eigenschaften des Torfes ab. Somit ist die Sackung des Torfes sehr kompliziert und ihre exakte Einschätzung mathematisch erschwert.

Die Methoden der Sackungsschätzung sind unvollkommen.

So ist die Beschaffenheit des Moores in der Tabelle von Gerhardt und in den Formeln von Panadiadi bloss subjektiv definiert. Da die Sackung der Moore von örtlichen klimatischen Bedingungen abhängt, tragen alle diese Methoden notwendigerweise auch einen örtlichen Charakter.

Die Intensität der Sackung ist von der Zeit abhängig und nimmt mit dieser ab, bis sie sich 2-5 Jahre nach der Entwässerung stabilisiert. Die Sackung des Torfes vor der Stabilisierung ist von der Entwässerung bedingt. Darauffolgende Sackungen, deren jährliche Grösse $1-2 \mathrm{~cm}$ beträgt, sind bedingt von der Zersetzung des Torfes.

Die von der Entwässerung der Moore verursachte Sackung ist geschuldet dem Setzen der unter den Dräns oder unter den Sohlen der Gräben befindlichen Moorschichten, sowie Abnehmen der Tiefen der Dräns oder Gräben. Die Sackung der unter den Dräns bleibenden Torfschichten hängt von der Mächtigkeit dieser Schichten, von der Tiefe der Dräns (oder Gräben) und vom Zersetzungsgrade des Torfes ab. In Abbildung 3 sind die Sackungen der Dräns im Niederungsmoortorfe, dessen Zersetzungsgrad $50 \%$ ist, dargestellt. Ist der Zersetzungsgrad des Torfes $40 \%$ oder $30 \%$, so sind die Sackungen entsprechend um $40 \%$ oder um $80 \%$ grösser. Relatives Abnehmen der Tiefen der Dräns (der Gräben) ist, wie es Beobachtungen beweisen, nur von den physikalischen Eigenschaften abhängig, die auch vom Zersetzungsgrad des Torfes bestimmt sind. Der Koeffizient $B$ des relativen Abnehmens der Tiefen der Dräns ist, je nach dem Zersetzungsgrade der Niederungsmoortorfe, aus der Tabelle 7 ersichtlich.

Für die Berechnung der Entwurfstiefen der Dräns ist eine entsprechende Formel (4) gegeben.

Der Aushub der Dränsgräben erfolgt meist einige Zeit nach dem Aushube der offenen Haupt- und Sammelgräben. Inzwischen setzt sich das Moor in der Wirkungszone des offenen Grabens, und diese Sackung ist um so grösser, je grösser die betreffende Zeitspanne ist. Die Sackung nimmt in den weiteren Zonen der offenen Gräben ab. So ist die Sackung des Torfes in der Nähe der Ausmündungsstellen der Dräns zu Beginn der Ausführungsarbeiten der Dräns beendet. Nach den Ausführungsarbeiten setzt sich der Boden der Dräns nur in den weiter entlegenen Zonen, und das Gefälle der Dräns nimmt ab. Deshalb ist es angezeigt, den Dräns in der Nähe der Ausmündungsstellen von vornherein ein grösseres Gefälle zu geben. 